\title{
Heart rate conditioning of goldfish, Carassius auratus, with intermittent vs. continuous CS
}

\author{
RICHARD T. ERSPAMER \\ Western Washington State College, Bellingham, Washington 98225 \\ and \\ MERLE E. MEYER \\ University of Florida, Gainesville, Florida 32611
}

\begin{abstract}
Within a respondent conditioning paradigm, the heart rate response (CHR) for goldfish was compared with CS, US, and pseudoconditioning controls with intermittent or constant CS (light). Goldfish showed a differential CHR (bradycardia) in the experimental condition, in contrast to the controls, and a greater level of CHR occurred under the intermittent CS condition.
\end{abstract}

Pavlov (1927/1960) made extensive use of various intermittent CSs in his research with dogs. However, Pavlov did not concern himself with the dynamics of CS. Comparing an intermittent and a continuous CS in conditioning the nictitating membrane response of the rabbit, Papsdorf, Fishbien, and Gormezano (1964) report that higher levels of conditioning were obtained in the intermittent CS condition as compared to the continuous CS. The present experiment was designed to replicate, in part, the Papsdorf et al. experiment with goldfish.

\section{METHOD}

\section{Subjects}

The subjects were 21 goldfish, Carassius auratus, acquired from Santian Aquarium, Brownsville, Oregon. The fish (15-20 cm long) were housed in a 300-1 aquarium measuring $120 \times 120 \times 120 \mathrm{~cm}$ for $1-4$ days prior to experimentation. The aquarium temperature was approximately $12^{\circ} \mathrm{C}$. Subjects were maintained on a photoperiod that approximated the normal seasonal environment, illumination occurred from 7:00 a.m. to $6: 00$ p.m.

\footnotetext{
Apparatus

A fish was placed in a clear plastic tank $27 \mathrm{~cm}$ long $\times 6 \mathrm{~cm}$ wide $\times 14 \mathrm{~cm}$ deep. The plastic tank was located inside a $45 \mathrm{~cm}$ long $\times 14 \mathrm{~cm}$ wide $\times 17 \mathrm{~cm}$ deep electrically shielded compartment. A constant . $5-1 / \mathrm{min}$ flow of charcoal-filtered water was circulated through the tank to provide an adequate supply of oxygenated water. Six $24-\mathrm{V}$ dc lamps, three located on either side of the shielded compartment, served as the CS. The US was a $1.5-\mathrm{sec} .050-\mathrm{mA}$ dc electric shock delivered through alligator clip electrodes. This intensity of shock resulted in a

This research is based upon a thesis submitted to the Department of Psychology, Western Washington State College, in partial fulfillment of the requirements for the MS degree by the senior author. Requests for reprints should be sent to Merle E. Meyer, Department of Psychology, University of Florida, Gainesville, Florida 32611.
}

reliable flinch or startle response in both species of fish. A polygraph was used to record the heart rate.

\section{Procedure}

The active electrode was fastened to the pectoral fin, the indifferent electrode to the tail fin, and the ground electrode to the dorsal fin. The fish was placed in the plastic tank and allowed to habituate for a period of $5 \mathrm{~min}$. The 35 trials for each treatment condition were divided into seven blocks of five trials each. A variable intertrial interval of $70 \mathrm{sec}$ was used for all treatment conditions except pseudoconditioning. Mean values were computed for three periods [last $10 \mathrm{sec}$ of the baseline (BS), CS, and the first $10 \mathrm{sec}$ immediately following the CS (P-US)] of each of the seven trial blocks.

\section{Treatment Conditions}

(1) Treatment 1 was a 20 -sec presentation of a constant CS with a US during the last $1.5 \mathrm{sec}$. (2) Treatment 2 was a US control where the US was presented without the CS. (3) Treatment 3 was a CS control that was identical to Treatment 1 except no US was presented. (4) Treatment 4 was a pseudoconditioning control. The CSs and USs were presented such that one CS and one US occurred within each of 35 segments of time (trials) that were equivalent to the amount of time required for the three periods (BS, CS, and P-US) plus $70 \mathrm{sec}$. There was no temporal relationship between the CS and US; they occurred randomly within the trial. (5) Treatment 5 was a flashing experimental condition [CS-US(FL)] with the presentation of a $20-\mathrm{sec}$ CS that flashed at a rate of $.5 \mathrm{sec}$ "on" to $.5 \mathrm{sec}$ "off," with a US during the last $1.5 \mathrm{sec}$. (6) Treatment 6 was a flashing CS control that was identical to the CS-US(FL) except no US was presented. (7) Treatment 7 was a pseudoconditioning control that was identical to Treatment 4 except a flashing CS was substituted for the constant CS.

\section{RESULTS AND DISCUSSION}

The analysis showed no significant changes in heart rate between periods (BS, CS, P-US) within trial blocks across trial blocks for all treatment conditions except the CS-US and the CS-US(FL). These comparisons suggest that the $\mathrm{CS}$ and $\mathrm{CS}(\mathrm{FL})$ were neutral stimuli, 
and there was no evidence of differential heart rate for the controls.

The CS period heart rate for the continuous CS condition was not different from the BS in Trial Blocks 1 and 2. However, it was significantly lower in the other trial blocks $(p<.01)$. Comparing the heart rate during the CS period across trial blocks revealed significant heart rate deceleration $(p<.01)$ from Trial Block 2 to Block 5 with an increase during Trial Blocks 6 and 7; Trial Blocks 3, 4, and 7 were approximately equal.

The CS(FL) condition revealed that the heart rate during the CS(FL) was not different from the BS on Trial Block 1. However, the heart rates on Trial Blocks $2-7$ were significantly lower $(p<.01)$. Comparing the heart rate across trials, all trial blocks differed from Trial Block 1, and Trial Block 3 was significantly lower than all other trial blocks $(\mathrm{p}<.01)$.

Heart rate during the CS(FL) period was significantly lower $(\mathrm{p}<.01)$ than the constant CS in Trial Blocks 2-7. This suggests that the magnitude of the conditioned heart rate to the flashing CS was greater than the magnitude of response to the constant CS.

This experiment further confirmed the findings of previous investigators concerning conditioning of heart rate in goldfish (Bernstein, 1961, 1962; McCleary,
1960; McCleary \& Bernstein, 1959; Otis, Cerf, \& Thomas, 1957). Furthermore, while conditioning was observed with both the continuous and intermittent CSs, the intermittent or flashing CS was found to be a more significant elicitor of the conditioned heart rate.

\section{REFERENCES}

Bernstein. J. J. Brightness discrimination following forebrain ablation in fish. Experimental Neurology, 1961, 3, 297-306.

BERNSTEIN. J. J. Role of the telencephalon in color vision in tish. Experimental Neurology. 1962, 6. 173-185.

MCCleary, R. A. Type response as a factor in interocular transfer in the fish. Journal of Comparative and Physiological Psychology, 1960, 63, 311-321.

McCleary. R. A.. \& Bernstein. J. J. A unique method for control of brightness cues in study of color vision in fish. Physiological Zoology. 1959, 32, 248-292.

Otis. L. S.. Cerf, J. A.. \& Thomas, G. J. Conditioned inhibition of respiration and heart rate in the goldtish. Science, 1957. 126. 263-264.

Papsdorf. J. C.. Fishbein, H. D., \& Gormezano. I. A. A comparison of an intermittent versus continuous CS in classical conditioning of the nictitating membrane response of the rabbit. Psychonomic Science, 1964, 1. 305-306.

Pavlov. I. P. [Conditioned reflexes] (G. V. Anrep. Ed. and trans.). New York: Dover, 1960. (Originally published, 1927.)

(Received for publication February 23, 1979.) 